\section{Aspectos Evolutivos dos Hormônios}

\section{RESUMO}

A busca do conhecimento verdadeiro (ciência) foi sempre norteada pela lógica, que ganhou instrumentos poderosos da biotecnologia atual. Com esses novos recursos, a natureza está revelando a sua linguagem secreta (código genético), o seu vocabulário próprio (seqüências gênicas), e as suas características desde sempre aparentes em suas criaturas (fenótipos). Tendo a natureza preservado em seu patrimônio seres vivos de diferentes períodos evolutivos, os pesquisadores podem comparar os vestígios de substâncias (como os hormônios), preservados em espécies antigas e mais recentes, e tentar reconstituir o seu percurso ao longo dos milênios. Destarte, o presente trabalho aborda esses aspectos evolutivos ligados aos hormônios. (Arq Bras Endocrinol Metab 2002;46/3:291-298)

Descritores: Hormônios; Proto-Hormônios; Peptídios; Evolução

\begin{abstract}
Evolutionary Aspects of Hormones.

The search of the true knowledge (science) was always guided by the logic, which won powerful tools from the current biotechnology. With these new resources, nature is revealing its secret language (genetic code), its own vocabulary (gene sequences), and its characteristics from always apparent in its creatures (phenotypes). Having nature preserved in its patrimony living beings of different evolutionary periods, the investigators can compare the vestiges of substances (such as hormones), preserved in old and more recent species, and try to reconstitute their course along the millennia. The present work therefore approaches these evolutionary aspects linked to the hormones. (Arq Bras Endocrinol Metab 2002;46/3:291-298)
\end{abstract}

Keywords: Hormones; Protohormones; Peptides; Evolution

M UITO TEM SIDO ESCRITO acerca da evolução dos hormônios no sentido de "progresso" ou de "avanço" conceitual daqueles, mas pouco tem sido reservado à acepção "darwiniana" da palavra "evolução" aplicada aos hormônios, i.e., ao "darwinismo" ou doutrina transformista do naturalista inglês Charles Robert Darwin (1809-1882), que compôs um sistema de história natural cuja conclusão extrema é o parentesco fisiológico - no presente caso, das moléculas hormonais -, e a origem comum de todos os seres vivos, com a formação de novas espécies, por um processo de seleção natural $(1,2)$.

Ao contrário dos paleontologistas, os biólogos não possuem o equivalente de fósseis para estudar a evolução dos hormônios, por isso a preservação da similaridade das moléculas hormonais, através das diferentes espécies vivas, ajuda a esclarecer determinados aspectos evolutivos dos hormônios; em outras palavras, como as espécies existentes resultaram obrigatoriamente de uma duplicação gênica bem-sucedida, é possível rastrear a perspectivas

Moacir C. de Andrade Jr
Unidade de Endocrinologia e Metabologia, Hospital e Maternidade Santo Alberto, Manaus, $A M$.
Recebido em 10/10/01 Revisado em 08/01/02 Aceito em 08/02/02 
evolução dos hormônios através de suas seqüências gênicas remanescentes nas espécies sobreviventes; um exemplo claro disso podendo ser extraído de glicoproteínas como o TSH, o FSH e a hCG, cujas subunidades $\alpha$ e $\beta$ estão presentes em espécies tão antigas e díspares quanto os agnatos (ou ciclóstomos), de 450 milhões de anos atrás, até os mamíferos, de $220 \mathrm{mi}$ lhões de anos atrás, sugerindo um gene ancestral comum (3-5).

O inglês Francis Harry Compton Crick (1916), juntamente com o norte-americano James Dewey Watson (1928-), propuseram a estrutura em dupla hélice para a molécula de ADN em 1953, ganhando por isso o Prêmio Nobel em Fisiologia ou Medicina em 1962 (6-8).

O inglês Maurice Hugh Frederick Wilkins (1916-) compartilhou o mesmo Prêmio com aqueles dois cientistas pelas suas próprias contribuições para o esclarecimento dessa transferência de informação na matéria viva. Mas já em 1958, Crick havia predito a necessidade de uma disciplina chamada "Taxonomia Protéica", justamente para estudar as seqüências de aminoácidos das proteínas de um organismo, e compará-las com aquelas dos de outras espécies, o que, na acertada opinião de Crick, constituía a expressão fenotípica (aparência) mais delicada de um organismo, com vasto conteúdo de informação evolutiva (9).

As bactérias atuais constituem organismos procariontes (sem núcleos organizados nem estruturas membranosas em seus citoplasmas), e os registros fósseis indicam que organismos procariontes, semelhantes às bactérias, foram a única forma de vida na terra até 1,5 bilhão de anos atrás, tratando-se, portanto, dos primeiros seres vivos $(5,8)$.

O termo "filogênese", do grego transliterado phylon (significando "grupo"), e génesis (significando "origem"), foi criado pelo naturalista alemão Ernst Heinrich Haeckel (1834-1919) - fervoroso discípulo de Darwin -, para designar as relações de origem e parentesco entre os seres atuais e seus ancestrais, cabendo, todavia, a Haeckel a elaboração da primeira árvore filogenética (1879) de que se tem notícia (10).

Por conseguinte, em uma escala filogenética dos organismos vivos, os procariontes (a exemplo das bactérias), ocupam a parte inferior da escala, os eucariontes unicelulares (a exemplo das amebas), ocupam a parte média da escala, e os eucariontes pluricelulares (a exemplo dos artrópodes, dos vertebrados), ocupam a parte superior da escala (3), e substâncias semelhantes à insulina, à somatostatina, à calcitonina do tipo humano, ao TSH, dentre outras, já foram encontradas, respectivamente, no Aspergillus fumigatus, na Esche- richia coli, em Candida sp. e E. coli, no Clostridium perfringens (11).

"Prot(o)-" é um elemento de composição vocabular oriundo do grego significando "primeiro" (1). Um proto-hormônio, do inglês protohormone, constituiria assim uma forma (primordial) de hormônio também encontrável em seres primitivos, a exemplo da insulina nas bactérias e fungos, dos esteróides nos fungos, e dos opióides nas amebas (3,11-13). Nestas últimas, peptídios opióides foram capazes de inibir a pinocitose - um processo variante da fagocitose e equivalente de ingestão alimentar para as amebas -, efeito esse revertido pelo naloxano (um antagonista opióide) (3) (apenas a título de reparo histórico, cumpre assinalar que o zoólogo russo Ilya Metchnikoff foi o primeiro autor a utilizar o termo "fagocitose" [do grego transliterado phagein, comer] em 1883, e Lewis aquele de "pinocitose" em $1931[14,15])$.

O Dictyostelium discoideum é também um ser primitivo, uma ameba, cujas características sociobiológicas - ou comportamentais no meio ambiente constituem um modelo privilegiado de sistema para o estudo da ação de substâncias consideradas tanto hormônios quanto proto-hormônios (13):

Em parte pelas condições de crescimento do $D$. discoideum na natureza serem reproduzíveis in vitro (na presença de bactérias, como a $E$. coli ou a Aerobacter aerogenes, ou na ausência de bactérias, nas ditas "culturas axênicas" [6]), e

Em parte por seu crescimento ser manipulável in vitro, através de diferentes estímulos e inibições.

Com efeito, na natureza e em condições ótimas, o D. discoideum possui vida livre sob a forma unicelular e alimenta-se de bactérias e fungos, dividindo-se quase de hora em hora; quando esses alimentos exaurem-se, cessa também a divisão celular e o $D$. discoideum agrega-se a outros de sua espécie, tornandose aparentemente pluricelular sob a forma de um pseudoplasmódio; o sinal molecular para essa quimiotaxia, para a agregação desses organismos sendo o gradiente extracelular aumentado do AMPc por eles mesmos secretado, indicando a escassez de alimentos no meio (essas alterações morfogênicas "em fases", i.e., de ameba inativa à ameba achatada, em seguida arredondada e depois com pseudópodes prontos para a quimiotaxia, é manipulável in vitro após estímulo com o AMPc, e dessa maneira perfeitamente apreciável em condições experimentais) $(3,13,16)$.

Earl W. Sutherland Jr. (1915-1974) e sua equipe isolaram o AMPc em 1958, e assim o chamaram pelos átomos do único grupo fosfato da molécula de AMPc estarem arranjados sob a forma de um anel 
(17) (Sutherland Jr. foi agraciado com o Prêmio Nobel em Fisiologia ou Medicina em 1971).

Dessa maneira, a presença do AMPc em toda a escala filogenética o assemelharia a um "código metabólico generalizado" na expressão de Tomkins (1975, citado por Baulieu, 1990 [3]), sugerindo que a linguagem química do metabolismo celular é altamente preservada na natureza (3). Entretanto, essa linguagem diferiu na evolução das espécies: enquanto o AMPc (extracelular) comporta-se como um mensageiro químico primário para o $D$. discoideum afaimado, propiciando a sua agregação e sobrevivência, para outras espécies mais evoluídas, o AMPc (intracelular) comporta-se como um mensageiro químico secundário em resposta à ação de vários hormônios endócrinos tradicionais (mensageiros químicos primários), possibilitando assim o escurecimento da pele de sapo pelo hormônio estimulante dos melanócitos, ou a reabsorção de cálcio ósseo pelo hormônio paratireóide, dentre muitos outros exemplos (17).

No homem, o AMPc é um importante regulador da função celular, agindo como mensageiro químico secundário e podendo, todavia, apresentar níveis plasmáticos elevados em pacientes urêmicos (apesar dos níveis plasmáticos do AMPc normalmente refletirem a atividade biológica do hormônio paratireóide, não houve correlação entre esses níveis elevados em pacientes urêmicos e o grau do hiperparatireoidismo secundário) (18). Ao contrário, a elevação do AMPc nefrogênico foi, em uma casuística de 174 pacientes com hiperparatireoidismo primário confirmado por cirurgia, o estigma (sinal) mais seguro da doença (19).

Assim sendo, vale ressaltar que o AMPc constitui um dos poucos exemplos de mensageiros químicos confinados no meio intracelular do organismo cujos níveis na circulação geral têm valor fisiopatológico.

Já os níveis circulantes da acetilcolina (um neurotransmissor tradicional confinado nas fendas sinápticas), refletiriam tão-somente um extravasamento (spillover em inglês) de seus múltiplos sítios de ação, não possuindo interesse fisiopatológico reconhecido (4).

Dentre outros neurotransmissores tradicionais, a exemplo das catecolaminas, a norepinefrina (ou noradrenalina) mereceu aqui alguns comentários suplementares, pelo seu significado fisiopatológico no sangue parecer às vezes duvidoso à luz da literatura dos últimos 30 anos, especialmente no que concerne aos mecanismos da contra-regulação hormonal na emergência hipoglicêmica induzida pela insulina.

Fazendo então um apanhado desse longo período literário, foi possível concluir que tanto em nível animal (rato) quanto em nível humano, as concen- trações sangüíneas de epinefrina (ou adrenalina) são sempre superiores àquelas de noradrenalina na contraregulação insulínica (a noradrenalina sendo um importante regulador da liberação hipotalâmica de GHRH (22), mas sem resposta em crianças com deficiência de $\mathrm{GH}$, ao contrário da adrenalina, com resposta, apesar de baixa); que os níveis de ambas catecolaminas são proporcionalmente menores em pacientes diabéticos com neuropatia autonômica; que as concentrações plasmáticas de noradrenalina constituem um índice falível da atividade simpática neural, pela noradrenalina circulante poder derivar de atividades neuroniais locais e da medula supra-renal, e essas diferenças regionais constituírem empecilhos de análise (eis novamente a questão do spillover levantada por Niall em relação não somente à acetilcolina mas também ao TRH e a outras substâncias mais ou menos ubíquas (onipresentes) no organismo) (4,20-25).

No ver de Niall (4), esses confinamentos (em nível intracelular, em nível sináptico), além de outros mais elaborados (a exemplo das separações das substâncias circulando no sangue, daquelas circulando em espaços munidos de barreiras hematoteciduais naturais - como a hematoencefálica, a hematotesticular), permite que o mesmo hormônio sirva em diferentes sítios, dentro do mesmo organismo, regulando funções em locais diferentes (uma faceta da versatilidade evolutiva dos hormônios e das substâncias a eles relacionadas).

Entretanto, esses aspectos devem ser apreciados de maneira crítica, considerando a intensa dinâmica de funcionamento dos seres vivos.

A insulina, p.ex., atravessa a barreira hematoencefálica via transcitose mediada por receptor (figura 1), o que tem sido correlacionado com o transporte concomitante aumentado de outras substâncias periféricas (um análogo da metencefalina produz analgesia no SNC e tem o seu transporte aumentado na dependência da dose de insulina administrada, com potencial interesse fisiopatológico sobre a nocipercepção dos pacientes diabéticos) (26).

A glicose figura dentre os principais substratos que podem ser utilizados como fonte direta de energia pelos diferentes tecidos do homem e dos mamíferos, no entanto, apenas dois órgãos, o fígado e o rim, possuem o equipamento enzimático (glicose-6-fosfatase), totalmente a montante do processo inicial de glicogenólise, e capaz de liberar a glicose armazenada sob a forma de glicogênio intracelular (27). Dessa maneira, sob a ação da glicose-6-fosfatase, $90 \%$ da glicose hepática se torna livre para circular no sangue após a perda do fosfato na posição 6 de seu esqueleto hidrocarbônico; $10 \%$ da glicose livre provindo assim mesmo do 
rim (27) (daí a importância do débito renal de glicose na correção das crises hipoglicêmicas).

A atividade enzimática da glicose-6-fosfatase não é, todavia, exclusiva dos organismos mais complexos, já tendo sido encontrada no Limulus (28), um parente próximo das aranhas e escorpiões (10).

Tamanha é a importância energética da glicose em toda escala filogenética que sua limitação experimental engendrou adaptações mutacionais em culturas de E. coli (29).

No homem, a importância da glicose no metabolismo energético, via o comportamento alimentar, é muito complexa, encontrando-se também esboçada na figura 1 (em longo prazo, insulina e leptina têm ações sinérgicas, mas seus transportes para o SNC são diferentes).

Já a evolução dos receptores parece ter seguido mais ou menos pari passu àquela de seus respectivos hormônios na diversificação da escala filogenética (3). Em outros termos, os receptores também mudaram mais ou menos com a diferenciação das espécies.

Em favor desse argumento foram encontrados materiais fixadores de hormônios "parecidos" com aqueles dos receptores de vertebrados, p.ex., na Pseudomonas maltophilia para a hCG, na E. coli e na Yersinia enterocolitica para o TSH, na Amoeba proteus para os opióides, na Candida albicans para a corticosterona, em Saccharomyces cerevisiae para os estrogênios, e assim por diante (11).
Outros aspectos evolutivos atrelados à ligação dos hormônios a seus receptores, e conseqüente sinalização intracelular da informação assim veiculada, também parecem ter seguido mais ou menos pari passu à evolução da diversificação da escala filogenética.

Por certo, os efeitos biológicos de muitos hormônios (polipeptídios, aminas) são transmitidos pela interação com seus receptores específicos existentes nas superfícies celulares, e pela subseqüente ativação da enzima "adenilato ciclase" ligada às membranas (na realidade, um complexo protéico formado pelos próprios receptores hormonais (um de inibição e outro de estimulação), por uma unidade catalítica responsável pela transformação do ATP em AMPc, e pela tríplice unidade reguladora da guanina - um nucleotídeo com um componente $\alpha$ com capacidades de estimulação e de inibição melhor conhecidas, e componentes $\beta$ e $\gamma$ menos conhecidos) (30-32). Em suma, a ligação do hormônio a seu receptor produz uma mudança na conformação desse complexo, interagindo primeiro com os componentes $\beta$ e $\gamma$, e em seguida com o componente $\alpha$ de acordo com a natureza estimulante ou inibidora do receptor ativado, resultando, respectivamente, no aumento ou na diminuição do AMPc intracelular, e no efeito biológico coligado (31).

$\mathrm{Na}$ moderna classificação dos seres vivos, "metazoa" é um termo reservado ao reino em que se enquadram todos os animais (daí serem chamados "metazoários"), desde os espongiários até o homem

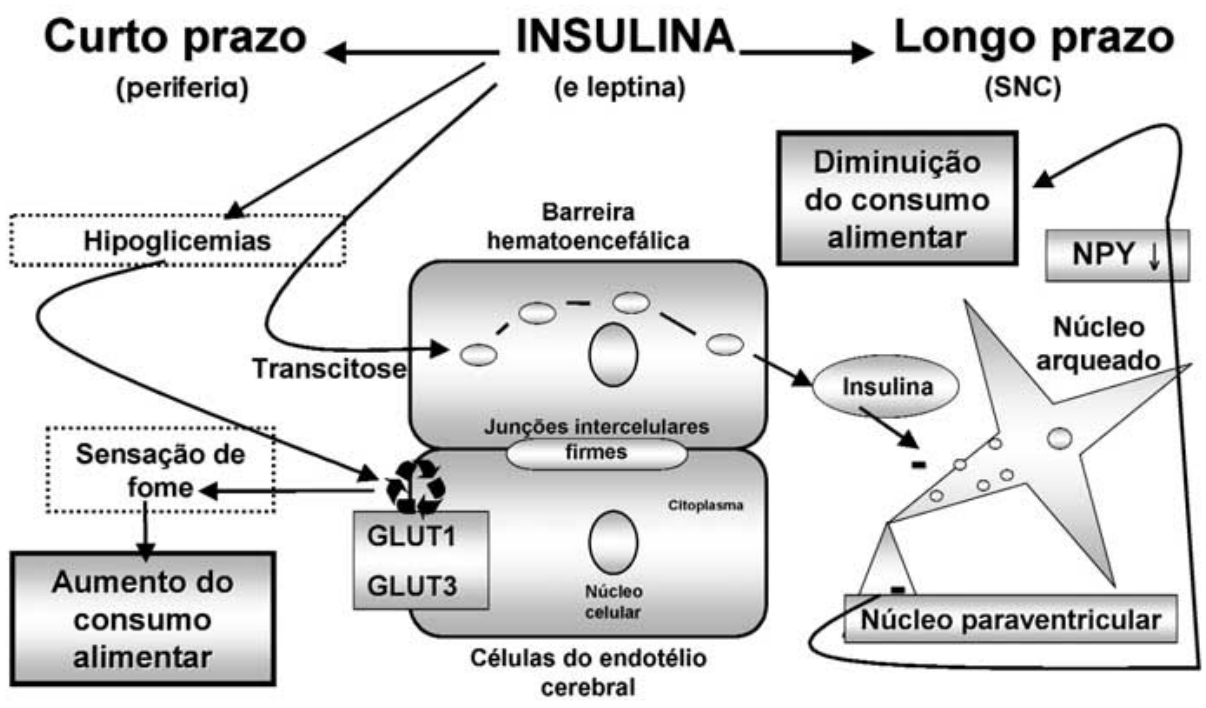

Figura 1. Presente tanto em organismos inferiores quanto superiores da escala filogenética, a insulina pode ser considerada um exemplo de proto-hormônio essencial no metabolismo energético global, em especial dos glicídios. 
(33), e os receptores com sete domínios atravessando as membranas celulares, e acoplados às proteínas G (com suas sub-unidades $\alpha, \beta$ e $\gamma$ ), representam um importante grupo de receptores para os metazoários, embora em um estudo utilizando ADN complementar de Geodia cydonium (uma esponja marinha pertencente à categoria mais inferior dos metazoários), a homologia da sub-unidade $\alpha$ tenha-se mostrado a mais constante dentre as diferentes espécies da categoria (há portanto um traço evolutivo comum nos sistemas efetores dos metazoários) (32).

Ao contrário, e segundo Litwack \& Schmidt (31), a heterologia parece atingir não somente as subunidades $\beta$ e $\gamma$ mas também a sub-unidade $\alpha$ das proteínas G. Isso está de acordo com os resultados dos estudos de Soppa em halobactérias (34).

Com efeito, o pigmento fotossintético das halobactérias não é a clorofila, mas o retinal, um pigmento visual também presente na retina do olho dos vertebrados, e a membrana das halobactérias contém moléculas de retinal combinadas a proteínas, formando o complexo conhecido como "bacteriorrodopsina" (14), geralmente considerado um modelo dos receptores acoplados às proteínas $\mathrm{G}$ dos eucariontes (34). O estudo de Soppa (34), baseado na comparação das seqüências de oito membros da família das proteínas retinais das halobactérias, com aquelas dos receptores acoplados às proteínas $\mathrm{G}$ dos eucariontes, não indicou ligação evolutiva entre essas duas famílias.

Por conseguinte, esses estudos tenderam a mostrar mais dessemelhanças do que semelhanças na evolução das proteínas $\mathrm{G}$ (importantes intermediários entre os receptores e os sistemas efetores celulares), e Soppa pôs assim em questionamento a validade de duas hipóteses:

A do exon shuffling (em inglês), ou literalmente "éxon arrastado" em português, e;

A da "duplicação gênica", tentando explicar a homologia da estrutura da bacteriorrodopsina com aquela dos receptores acoplados às proteínas $\mathrm{G}$ dos eucariontes (34).

De acordo com Garnier e os Delamare (35), "éxon" é a parte do ADN que codifica a informação gênica, e o termo remonta a 1977, ao passo que "íntron" é o inverso, mas remontando também à mesma época. A título de ressalva, exon shuffling, assim como intron insertion (em inglês, ou "inserção de íntron"), constituem apenas exemplos da série de eventos evolutivos que acompanha a duplicação gênica das espécies ao longo do tempo (36).

Segundo a teoria do exon shuffling de Gilbert (1985, citado por Goldstein e cols., 1995 [37]), éxons que codificam domínios protéicos funcionais são reutilizados durante a evolução.

Uma sinopse sobre intron insertion encontra-se nesta referência $(38)$.

Por fim, analisando os aspectos evolutivos dos hormônios peptídicos, Niall destacou quatro preceitos bastante difundidos, os quais resumiu com a seguinte linguagem coloquial (4):

"A duplicação gênica constitui a regra do jogo" (muitos hormônios peptídicos existem sob a forma de "famílias" com enorme homologia em suas seqüências de aminoácidos - famílias de hormônios afins à insulina, à prolactina, aos hormônios digestivos, aos hormônios glicoprotéicos de origem hipofisária (o TSH e o FSH já mencionados) e placentária, como a hCG também já mencionada);

"Tudo é feito em todo lugar" (hormônios pituitários são encontrados no cérebro e na placenta; a somatostatina é encontrada no trato gastrintestinal e nas ilhotas pancreáticas, assim como no hipotálamo; moléculas muito semelhantes ao LHRH têm sido encontradas nas gônadas e na placenta; hormônios gastrintestinais, a exemplo da colecistocinina e da gastrina, estão presentes no cérebro);

"Nunca faça um novo hormônio quando puder utilizar um antigo" (biólogos, especialmente os zoólogos, já notaram que a natureza é parcimoniosa na utilização de seus recursos, disponibilizando sempre os mesmos mecanismos bem-sucedidos, a exemplo do mimetismo (ou coloração protetora) de várias maneiras por diferentes espécies; o mesmo aplicandose à evolução de receptores de velhos hormônios em novos alvos teciduais, a exemplo da prolactina, que pode adaptar o peixe a diferentes concentrações de sal na água, e preparar a glândula mamária para a nutrição de mamíferos jovens). De fato, a principal ação fisiológica da prolactina nos mamíferos é de estimular a transcrição gênica da caseína e aumentar a tradução de seu ARN mensageiro, favorecendo assim a biossíntese da caseína do leite (39).

"Conservação de estrutura = função" $(\mathrm{com}-$ parando seqüências de aminoácidos capazes de codificar determinados hormônios, é plausível questionar como certas regiões puderam ser preservadas?).

Esses dois últimos preceitos foram especialmente reunidos em uma "hipótese unitarista" proposta por Ottaviani e cols. (40), na qual a evolução favorece o que tem sido conservado ("nunca faça um novo hormônio quando puder utilizar um antigo" [4]), preferivelmente ao que tem sido mudado, pelo menos no que tange às moléculas e às suas funções ("conservação de estrutura = função" [4]), em um 


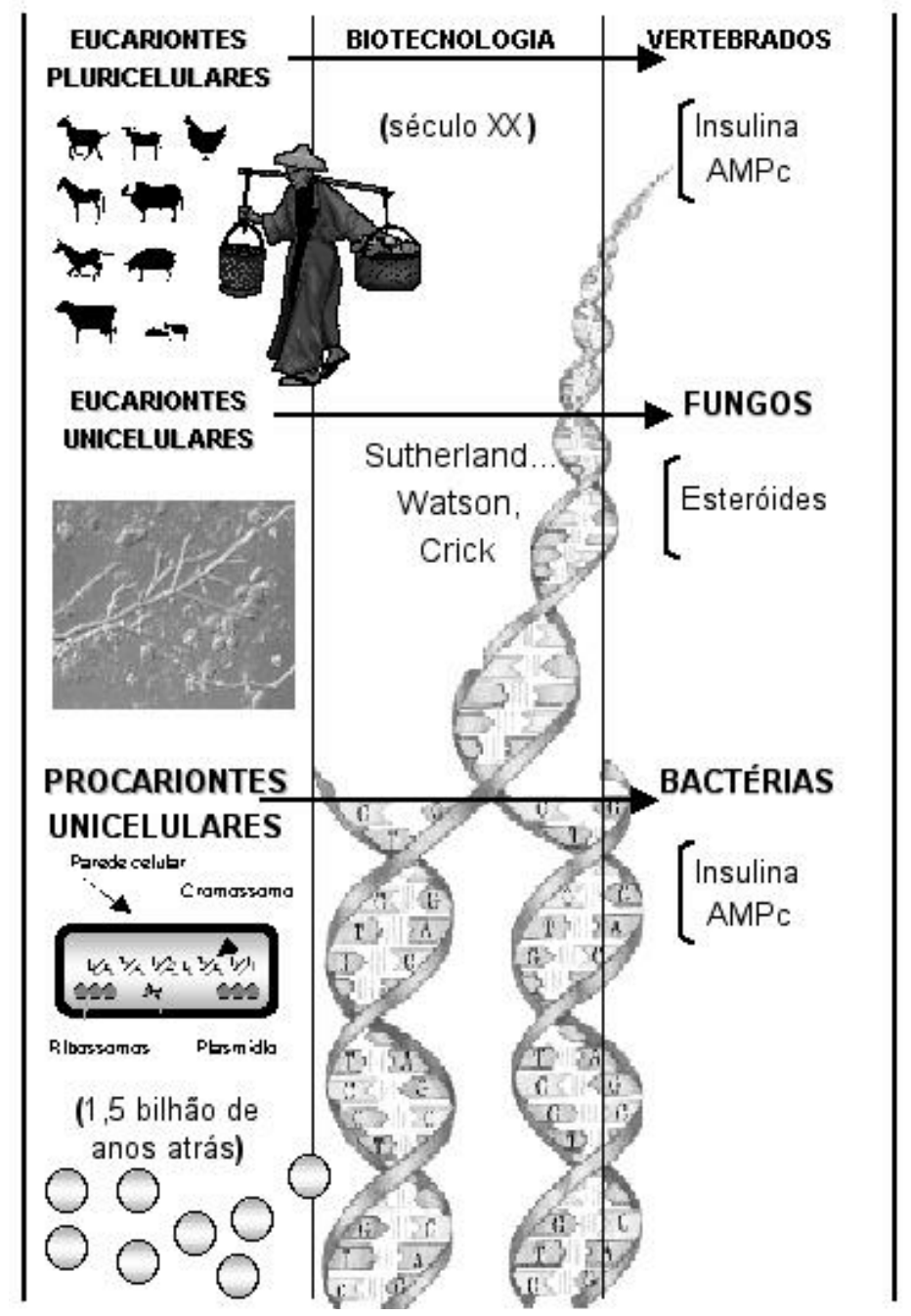

Figura 2. Escala Filogenética (coluna esquerda), desvendando através da Biotecnologia (coluna intermediária), os Proto-Hormônios e o principal mensageiro químico secundário,o AMPc (coluna direita).

processo em que a reação inflamatória ("óxido nítrico" em destaque) situa-se entre a resposta imune ("macrófagos" e "citocinas" em destaque) e o estresse ("sistema neuroendócrino" em destaque através dos produtos da POMC, das aminas biogênicas e dos hormônios esteróides), compartilhando as mesmas raízes evolutivas desde o começo da vida na terra.

A insulina é secretada pelas células $\beta$ das ilhotas pancreáticas sob a influência de vários eixos de regulação, sendo o da glicose alimentar o principal, e todos os outros menos importantes, a ex. do eixo de regulação cérebro-insular (via acetilcolina), do êntero-insular (via o peptídio inibidor gástrico), ou da regulação parácrina, na qual os diferentes componentes celulares das ilhotas pancreáticas ( $\alpha$ ou produtor de glucagon, $\beta$ ou produtor de insulina, $\delta$ ou produtor de somatostatina, e "PP" ou produtor do polipeptídio pancreático), influenciam as secreções uns dos outros (41).

Estudando precisamente alguns aspectos evolutivos dos hormônios intestinais e insulares, Van Noorden e Falkmer (42) concluíram que a localização da insulina em vertebrados tão antigos quanto os ciclóstomos (já mencionados) e os peixes, sugere que ela foi, em termos filogenéticos, o primeiro hormônio das ilhotas pancreáticas, seguido pela somatostatina, o glucagon e finalmente o polipeptídio pancreático.

Há decerto muitos aspectos pertinentes ainda obscuros, mas as investigações nessa área são de grande interesse científico e continuam progredindo (ver a figura 2). 


\section{AGRADECIMENTOS}

Aos Funcionários da Biblioteca do Instituto Nacional de Pesquisas da Amazônia (INPA), pelo auxílio cordial na pesquisa bibliográfica.

\section{REFERÊNCIAS}

1. Ferreira $A B H$. Novo Aurélio Século XXI: o Dicionário da Língua Portuguesa. Rio de Janeiro:Nova Fronteira, 1999.

2. Russ J. Dicionário de Filosofia. São Paulo:Scipione, 1994

3. Baulieu EE. Hormones: a complex communication network. In: Baulieu EE, Kelly PA, editors. Hormones: from molecules to diseases. $1^{\text {st }}$ ed. Paris:Hermann, 1990;1-169.

4. Niall HD. The evolution of peptide hormones. Ann Rev Physiol 1982;44:615-24.

5. Amabis JM, Martho GR. Biologia das populações: Genética, evolução e ecologia. São Paulo:Moderna, 1998.

6. Parker SP, editor. McGraw-Hill Dictionary of Scientific and Technical Terms. New York:McGraw-Hill, 1984.

7. Medvei VC. The history of clinical endocrinology. Lancs:Parthenon , 1993.

8. Jorde LB, Carey JC, Bamshad MJ, White RL. Genética médica. Rio de Janeiro:Guanabara Koogan, 2000

9. Fitch WM, Margoliash E. The usefulness of amino acid and nucleotide sequences in evolutionary studies. Evolutionary Biol 1970;4:67-109.

10. Amabis JM, Martho GR. Biologia dos organismos: Classificação, estrutura e função nos seres vivos. São Paulo:Moderna, 1994

11. LeRoith D, Delahunty $G$, Wilson GL, Roberts Jr CT, Shemer $\mathrm{J}$, Hart $\mathrm{C}$, et al. Evolutionary aspects of the endocrine and nervous systems. Recent Prog Horm Res 1986;42:549-87.

12. Korneev A, Ershov Fl. Interferon - parahormone or protohormone. Vopr Virusol 1987;32:753-6.

13. Krichevsky MI, Love LL. The growth and utilization of Dictyostelium discoideum as a model system for hormone and protohormone action. Methods Enzymol $1975 ; 485-92$

14. Amabis JM, Martho GR. Biologia das células: Origem da vida, citologia, histologia e embriologia. São Paulo:Moderna, 1994.

15. Pessôa SB, Martins AV. Pessôa Parasitologia médica. Rio de Janeiro:Guanabara Koogan, 1978

16. Alberts B, Bray D, Lewis J, Raff M, Roberts K, Watson JD. Molecular biology of the cell. New York:Garland, 1994.

17. Pastan I. Cyclic AMP. Sci Am 1972;227:97-105.

18. Llach F, Bover J. Renal osteodystrophy. In: Brenner BM, editor. Brenner and Rector's the kidney. $5^{\text {th }}$ edition. Philadelphia:W.B.Saunders, 1996;2187-273.

19. Hazard J, Perlemuter L, Bougnères P. Abrégé d'endocrinologie. 3ème éd. Paris:Masson S.A., 1989.

20. Fujino Y, Fujii T. Insulin-induced hypoglycemia stimulates both adrenaline and noradrenaline release from adren- al medulla in 21-day-old rats. Jpn J Pharmacol 1995;69:413-20.

21. Vollmer RR, Balcita JJ, Sved AF, Edwards DJ. Adrenal epinephrine and norepinephrine release to hypoglycemia measured by microdialysis in conscious rats. Am J Physiol 1997:273:R1758-63.

22. Voorhess ML, MacGillivray MH. Low plasma norepinephrine responses to acute hypoglycemia in children with isolated growth hormone deficiency. J Clin Endocrinol Metab 1984;59:790-3.

23. Horie $\mathrm{H}$, Hanafusa T, Matsuyama T, Namba M, Nonaka K, Tarui S, et al. Decreased response of epinephrine and norepinephrine to insulin-induced hypoglycemia in diabetic autonomic neuropathy. Horm Metab Res 1984; 16:398-401.

24. Hilsted J, Christensen NJ, Larsen S. Norepinephrine kinetics during insulin-induced hypoglycemia. Metabolism 1985;34:300-2.

25. Paramore DS, Fanelli CG, Shah SD, Cryer PE. Forearm norepinephrine spillover during standing, hyperinsulinemia, and hypoglycemia. Am J Physiol 1998;275:E872-81.

26. Witt KA, Huber JD, Egleton RD, Davis TP. Insulin enhancement of opioid peptide transport across the blood-brain barrier and assessment of analgesic effect. J Pharmacol Exp Ther 2000;295:972-8

27. Girard J, Assan R. Régulation intracellulaire du métabolisme des substrats énergétiques. In: Tchobroutsky $G$, Guy-Grand B, editors. Nutrition, métabolismes et diététique. 2ème éd. Paris:Flammarion Médecine-Sciences, 1979:31-69.

28. Stetten MR, Goldsmith PK. A Limulus glucose-6-phosphatase with phosphotransferase activity characteristic of vertebrate liver microsomes. Its possible evolutionary significance. Biochim Biophys Acta 1976 : 444(3):835-52.

29. Manch K, Notley-McRobb L, Ferenci T. Mutational adaptation of Escherichia coli to glucose limitation involves distinct evolutionary pathways in aerobic and oxygenlimited environments. Genetics 1999; 153(1):5-12.

30. Aurbach GD. Polypeptide and amine hormone regulation of adenylate cyclase. Ann Rev Physiol 1982;44:653-66.

31. Litwack $G$, Schmidt TJ. Biochemistry of hormones I: polypeptide hormones. In: Devlin TM, editor. Textbook of biochemistry with clinical correlations. $4^{\text {th }}$ ed. New York:Wiley-Liss, 1997:839-91

32. Seack J, Kruse M, Muller WE. Evolutionary analysis of $G$ proteins in early metazoans: cloning of alpha- and betasubunits from sponge Geodia cydonium. Biochem Biophys Acta 1998; 1401:93-103.

33. Soares JL. Dicionário etimológico e circunstanciado de biologia. São Paulo:Scipione, 1993.

34. Soppa J. Two hypotheses one answer. Sequence comparison does not support an evolutionary link between halobacterial retinal proteins including bacteriorhodopsin and eukariotic G-protein-coupled receptors. FEBS Lett 1994;342:7-11.

35. Garnier M, Delamare V, Delamare J, Delamare J, Delamare F. Dictionnaire des termes techniques de médecine. 21 ème éd. Paris:Maloine S.A., 1985. 
36. Perret C, Lomri N, Thomasset M. Evolution of the EF-hand calcium-binding protein family: evidence for exon shuffling and intron insertion. J Mol Evol 1988;27:351-64.

37. Goldstein JL, Hobbs HH, Brown MS. Familial hypercholesterolemia. In: Scriver CR, Beaudet AL, Sly WS, Valle D, editors. The metabolic and molecular bases of inherited disease. $7^{\text {th }}$ ed. New York:McGraw-Hill, 1995; 1981-2030.

38. Strauss E. Targeting intron insertion into DNA. Science 2000;289:374.

39. Schaison G. Pathologie de la prolactine. In: MauvaisJarvis $P$, Sitruk-Ware $R$, editors. Médecine de la reproduction: Gynécologie endocrinienne. 2ème éd. Paris:Flammarion Médecine-Sciences, 1986;360-84

40. Ottaviani E, Franchini A, Franceschi C. Pro-opiomelanocortin-derived peptides, cytokines, and nitric oxide in immune responses and stress: an evolutionary approach. Int Rev Cytol 1997;170:79-141.
41. Portha B. Production et sécrétion de l'insuline par la cellule B pancréatique. Encycl Méd Chir (EndocrinologieNutrition) 1996; 10-362-E-10.

42. Van Noorden S, Falkmer S. Gut-islet endocrinology some evolutionary aspects. Invest Cell Pathol 1980;3:21-35.

\section{Endereço para correspondência:}

Moacir C. de Andrade Jr

Rua Comendador Alexandre Amorim, 253 B

69010-300 Manaus, AM

Fax: (092) 633-8028

e.mail: moacir@netium.com.br / moacir@internext.com.br 